\title{
Expression of a rat vasopressin transgene in rat testes
}

\author{
Q. Zeng, N-C. Foo, J. M. Funkhouser, D. A. Carter and D. Murphy* \\ Neuropeptide Laboratory, Institute of Molecular and Cell Biology. Singapore 0511, Republic of Singapore
}

The rat vasopressin gene contains two transcriptional promoters; the activity of one is confined to the hypothalamus, while the other is testis specific. To define the sequences mediating the cell-specific expression of the vasopressin gene, we introduced rat vasopressin transgenes into the rat germ line. Neither transgene 1.5-V $\beta$ gal-0.2, which consists of the entire vasopressin structural gene containing a $3 \mathrm{kbp} \beta$-galactosidase reporter element in exon III, flanked by $1.5 \mathrm{kbp}$ upstream of the start of hypothalamic transcription and $0.2 \mathrm{kbp}$ downstream of the polyadenylation site, nor transgene 3-V $\beta$ gal-0.2, which consists of the entire VP structural gene containing a $3 \mathrm{kbp} \beta$-galactosidase reporter element in exon III, flanked by $3 \mathrm{kbp}$ upstream of the start of hypothalamic transcription and $0.2 \mathrm{kbp}$ downstream of the polyadenylation site, were expressed in the hypothalamus. This contrasts with a previously described transgene consisting of the rat vasopressin structural gene containing a reporter in exon III, flanked by $5 \mathrm{kbp}$ of upstream and $3 \mathrm{kbp}$ of downstream sequences, which is expressed in vasopressinergic hypothalamic neurones. Both the 3-V $\beta$ gal-0.2 and 1.5-V $\beta$ gal-0.2 transgenes were expressed in testicular germ cells using a promoter located within the $\beta$-galactosidase reporter element. Transgene RNA was most abundant during the late stages of meiosis. Rats bearing vasopressin- $\beta$-galactosidase transgenes provide new models for the study of the mechanisms whereby an epigenetic choice is made between the use of a germ cell or a somatic promoter, and the stage-specific transcriptional regulation of a germ cell promoter during spermatogenesis.

\section{Introduction}

Gene expression during spermatogenesis (Willison and Ashworth, 1987) has been the subject of much interest, and studies have revealed unusual features not shared by other developmental systems. In particular, a number of genes expressed in somatic cells have also been found to be expressed in the male germ line, but using distinct, spermatogenic cell-specific promoters (Ivell, 1992). Some neuropeptide genes exhibit such properties, including the genes encoding rat and mouse preproenkephalin (Kilpatrick ef al., 1987, 1990) and rat vasopressin (VP; Foo et al., 1991, 1994; Lefebvre and Zingg, 1991).

The rat VP gene contains two tissue-specific transcriptional promoters (Foo et al., 1994). The activity of one of these elements is confined to neurones in the hypothalamus (Young, 1992), whereas the other is testis specific (Foo et al., 1991, 1994). Transcripts derived from the testis-specific promoter are probably present in germ cells (Foo et al., 1994). However, mechanistic studies on both the hypothalamic and testicular expression of the VP gene have been hampered by the lack of appropriate cell lines (Ivell and Burbach, 1991). We therefore chose to study the expression of the rat VP gene in transgenic rats. A transgene consisting of the rat VP structural gene containing a reporter in exon III, flanked by $5 \mathrm{~kb}$ of upstream and $3 \mathrm{~kb}$ of downstream sequences, is expressed in vaso-

*Correspondence.

Received 8 July 1994. pressinergic, but not oxytocinergic, magnocellular neurones of rats (Zeng et al., 1994). Functionally appropriate physiological stimuli markedly increase transgene expression in magnocellular neurones (Zeng et al., 1994). We sought to define the cis-acting sequences required for the cell-type-specific expression of the VP gene further by the introduction into the rat germ line of smaller transgenes. We found that transgenes consisting of the entire vasopressin structural gene containing a $3 \mathrm{kbp} \boldsymbol{\beta}$-galactosidase reporter element in exon III, flanked by either $1.5 \mathrm{kbp}$ or $3 \mathrm{kbp}$ upstream of the start of hypothalamic transcription and $0.2 \mathrm{kbp}$ downstream of the polyadenylation site, are expressed in the testis. Here we describe the cellular location of this expression and define the promoter responsible.

\section{Materials and Methods}

\section{Transgene construction}

Clones corresponding to the rat VP gene were isolated (Sambrook et al,, 1989) from a Sprague-Dawley genomic library constructed in Charon $4 \mathrm{~A}$ using oligonucleotide probes corresponding to VP exon I (a 45mer corresponding to the last 15 amino acids of exon I; Foo et al., 1991) and exon III (a 48mer corresponding to the last 16 amino acids of exon III; Murphy et al., 1989). An $8.2 \mathrm{kbp}$ EcoRI fragment containing the entire VP structural gene (exons I, II and III) and $3 \mathrm{kbp}$ of upstream and $3 \mathrm{kbp}$ of downstream sequences (Fig. 1) was subcloned into pUC18 to give clone prVP8.2R1. A $3.8 \mathrm{kbp}$ HindIII fragment 
containing the entire VP structural gene and $1.5 \mathrm{kbp}$ of upstream sequences and $0.2 \mathrm{kbp}$ of downstream sequences (Fig. 1) was subcloned into pUC18 to give prVP3.8H3. This was cut with both HindIII, which cuts at the ends of the clone, and Sma I, which cuts twice in exon III liberating a $66 \mathrm{bp}$ fragment that was not incorporated into the subsequent constructs. Note that probes corresponding to this region (for example the oligonucleotide probe corresponding to the last 16 amino acids of exon III; Murphy ef al., 1989) will not hybridize to the corresponding transgenes or transcripts. The large $5^{\prime}$ fragment was subcloned into HindIII and Sma I cut pSP72 (Promega, Madison, WI) to generate pSP72rVP5', whilst the 240 bp $3^{\prime}$ end was subcloned into HindIII and Sma I cut pUC12, giving rise to pUC12rVP3'. The pSP72rVP5' was cut with Sma I and ligated to an 8mer containing a BamHI site (Pharmacia, Uppsala). After cleavage with BamHI and ligation of the ends to form a circle, the resulting clone was designated pSP72rVP5'B. The pSP72rVP5'B was digested with EcoRV, which cuts in the multiple cloning site downstream of the introduced Bam HI site. After ligation with an 8 mer containing a Sal I site (Pharmacia), vector was prepared by gel purification following EcoRI and Sal I digestion. The ends generated by HindIII digestion of pUC12rVP3' were flushed with Klenow polymerase. After ligation of an 8 mer Sal I linker, an insert was prepared by gel purification following EcoRI and Sal I digestion. Vector and insert were ligated to create pSP72rVP5 $5^{\prime} 3^{\prime}$. This clone consists of the VP structural gene, $1.5 \mathrm{~kb}$ of upstream sequences and $0.2 \mathrm{~kb}$ of downstream sequences. Compared with the wild-type gene, $66 \mathrm{bp}$ corresponding to the Sma I fragment in exon III have been deleted and replaced with a number of restriction sites (in order: Bam HI, Kpn I, Sac I, EcoRI, Sac I, Sma I). Construct 1.5-Vßgal-0.2 was generated by the insertion of a $3.0 \mathrm{kbp}$ Bam HI fragment containing the entire $\beta$-galactosidase ( $\beta$-gal) gene derived from plasmid pMC-1871 (Pharmacia) into the unique BamHI site of pSP72rVP5'B3'. The design of this construct resulted in the $\beta$-gal reporter being placed in frame in exon Ill. The transgene fragment was excised from the vector by digestion with HindIII and Sal I and purified for microinjection into fertilized rat eggs (Murphy and Hanson, 1987; Murphy and Carter, 1993). Additional upstream sequences were inserted into 1.5-V $\beta$ gal-0.2 to generate $3-\mathrm{V} \beta \mathrm{gal}-0.2$. The ends generated by EcoRI digestion of prVP8.2RI were flushed with Klenow polymerase. After addition of 8 mer Xhol linkers (Pharmacia), upstream sequences were liberated by digestion with HindIII and Xhol. This fragment was inserted into 1.5-VBgal-0.2 that had been cut to completion with HindIII, and partially with Xhol, which cuts both in the pSP72 multiple cloning site and in VP promoter sequences just downstream of the HindIII site (Fig. I), thus creating 3-Vßgal-0.2. The transgene fragment was excised from the vector by complete digestion with Sal I followed by partial digestion with Xhol, and purified for microinjection into fertilized rat eggs (Murphy and Hanson, 1987; Murphy and Carter, 1993).

\section{Animals and treatments}

All wild type and transgenic Sprague-Dawley rats used in this study were bred on site. Animal studies were conducted in accordance with the principles and procedures outlined in the National Institute of Health Guide for the Care and Use of Laboratory Animals. Germ cells were depleted by lower abdominal heat treatment (Collins and Lacy, 1969). Male Sprague-Dawley rats, $200-250 \mathrm{~g}$, were anaesthetized by i.p. injection of $0.7 \mathrm{ml} \mathrm{CRC} \mathrm{cocktail} \mathrm{(} 1$ volume of Hypnorm [Diazepam, fentanyl citrate and fluanisone], 1 volume of Dormicum and 2 volumes of water). The scrotal regions of the animals were then submerged in a $42^{\circ} \mathrm{C}$ water bath for $30 \mathrm{~min}$. Control rats were allowed to recover from the anaesthetic without any heat treatment. After recovery for 1 week, animals were killed by decapitation and testes were removed and weighed. The right testis was processed for histological analysis (Foo et al., 1994), while RNA was extracted from the left testis.

\section{Generation of transgenic rat lines}

Transgenic rats were derived by microinjection of fertilized one-cell Sprague-Dawley rat eggs as described (Murphy and Carter, 1993). After positive identification of a transgenic rat founder by Southern hybridization analysis, lines were generated through crosses with wild-type Sprague-Dawley mates. At each generation, obligate heteroxygote transgenic rats were identified by Southern hybridization and used in expression studies.

\section{Isolation and analysis of RNA}

Total cellular RNA was extracted from rat tissues and analysed by northern blotting as described by Ang et al. (1991). RNA samples were loaded onto gels in ethidium bromide ( $1 \mathrm{mg} \mathrm{ml}^{-1}$ ). After transfer from the gel to Hybond-N (Amersham Ltd., Amersham), the quantity and integrity of the RNA was monitored by visualization under ultraviolet light. Antisense oligonucleotide northern hybridization probes were synthesized (Dr Ben Li, National University of Singapore) and $5^{\prime}$ end-labelled with polynucleotide kinase (New England Biolabs, Beverly, MA) and $\gamma_{-}{ }^{32}$ P ATP (Amersham). The VP3' probe is a 48 mer corresponding to the sequences encoding the last 16 amino acids of VP exon III (Murphy et al., 1989). The VP5' probe is a $45 \mathrm{mer}$ corresponding to the sequences encoding the last 15 amino acids of exon I (Foo et al., 1991). The VPNP probe is a 49 mer derived from sequences in exon II shared with the oxytocin (OT) gene (Foo et al., 1991). The glyceraldehyde-3-phosphate dehydrogenase (GAPDH) oligonucleotide corresponds to nucleotides 361-404 of the rat cDNA (Fort et al., 1985). The following oligonucleotides were synthesized on the basis of the sequence of $\beta$-galactosidase ( $\beta$-gal; Kalnins et al., 1983): $\beta$-galA is a 48 mer corresponding to nucleotides $2881-2928$ of the LacZ gene; $\beta$-galB is a $25 \mathrm{mer}$ corresponding to nucleotides $1760-1784$ of the LacZ gene. Polyadenylated RNA was isolated from total cellular preparations using the Invitrogen (San Diego, CA) Fast Track system or by poly(U) Sepharose chromatography (Clemens, 1984). Primer extension analysis was described by Treizenberg (1990). Poly(A) tails were removed from RNAs by hybridization to oligo dT (Pharmacia) followed by RNase $\mathrm{H}$ digestion (Carrazana et al., 1988). 


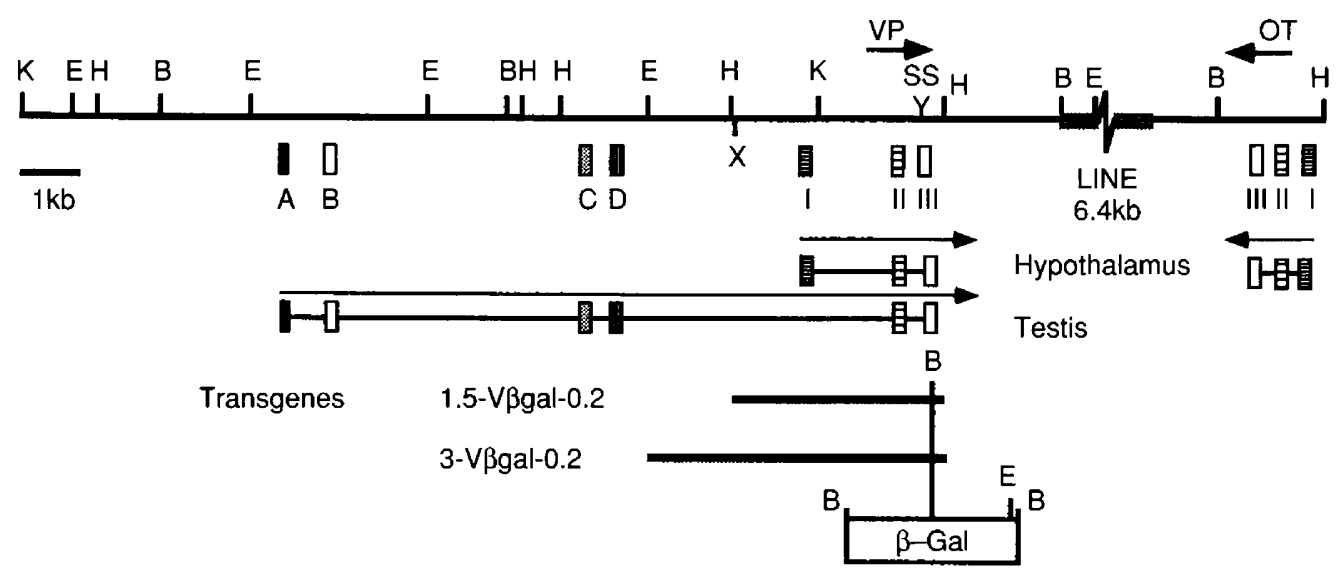

Fig. 1. The structure of the two transgenes, 1.5-Vßgal-0.2 and 3-V $\beta$ gal-0.2 compared to the endogenous genomic structure. Two tissue-specific promoters are present in the rat vasopressin (VP) gene. One is testis specific; the other is active in hypothalamic neurones. Boxes A-D represent the rat testis-specific exons spliced to exons II and III, which are also used in the hypothalamus. Closely linked to the VP gene is the gene encoding the hypothalamic neuropeptide, oxytocin (OT). The two genes, $11 \mathrm{kbp}$ apart in the rat genome, being separated by a $6.4 \mathrm{kbp}$ long interspersed repetitive element (LINE), are transcribed towards each other from opposite strands of the DNA duplex (horizontal arrows). Both VP and OT contain three exons (I-III) used in the hypothalamus. Restriction enzyme sites shown above the genomic map: K, KpnI; E, EcoRI; H, HindIII: B, Bam HI: X, XhoI; S, Sma I.

In situ analysis of transgene expression

Activity of $\beta$-gal was detected in tissue sections as described by Sanes et al. (1986). For in situ hybridization, transgenic rats and wild-type controls were fixed by transcardial perfusion. The initial perfusate was sodium phosphate buffered saline (PBS; pH 7.4) containing $5000 \mathrm{U}$ heparin sulphate $\mathrm{ml}^{-1}$. This was followed by picric acid paraformaldehyde fixative, $\mathrm{pH} 7.4$ (Zamboni and De Martino, 1967). After dissection, the perfused testes were cut into eight pieces, four of which were fixed for 2-3 $\mathrm{h}$ in picric acid paraformaldehyde $(\mathrm{pH} \mathrm{7.4)}$ and left overnight in PBS containing 30\% (w/v) sucrose. Tissue was frozen in isopentane cooled with dry ice-acetone, then stored at $-80^{\circ} \mathrm{C}$ for a maximum of 4 months. Frozen sections were cut at $10 \mu \mathrm{m}$, dried on a $45^{\circ} \mathrm{C}$ warm plate, then refrozen and stored at $-80^{\circ} \mathrm{C}$. The remaining dissected tissue blocks were fixed overnight in picric acid paraformaldehyde ( $\mathrm{pH} 7.4)$, then dehydrated and embedded in paraffin wax. Paraffin wax sections were cut at $5 \mu \mathrm{m}$. The tissue hybridization was performed by a modification of the techniques of Lightman and Young (1987). The embedded sections were deparaffinized for $10 \mathrm{~min}$

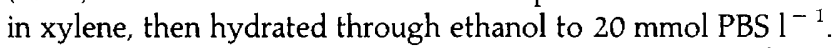
The sections were treated with proteinase $\mathrm{K}\left(2 \mu \mathrm{g} \mathrm{ml}^{-1}\right)$ for $10 \mathrm{~min}$ at $37^{\circ} \mathrm{C}$ and rinsed in $2 \%(\mathrm{w} / \mathrm{v})$ glycine and then PBS. Frozen sections were removed directly from the freezer into PBS. All sections were treated with acetic anhydride, delipidized with ethanol and chloroform, then air dried from $90 \%$ $(\mathrm{v} / \mathrm{v})$ ethanol. The $\beta$-galA oligonucleotide probe was labelled at the $3^{\prime}$ end using ${ }^{35} \mathrm{~S}$ dATP (NEN-DuPont, Boston, MA) and terminal deoxynucleotidyl transferase (NEN-DuPont). After hybridization overnight at $40^{\circ} \mathrm{C}$, sections were washed in saline sodium citrate for $1 \mathrm{~h}$ at $56^{\circ} \mathrm{C}$, and then at room temperature for $2 \mathrm{~h}$. Slides were dipped in NTB-2 emulsion (Kodak) and then exposed desiccated at $4^{\circ} \mathrm{C}$ for $1-5$ weeks before they were developed. The specificity of the in situ hybridization signal was controlled in two ways. First, random oligonucleotide probes gave no specific signal (data not shown). Second, wild-type rat testis, which is identical to transgenic testis except that it lacks the transgene RNA, revealed no signal with the BgalA probe.

\section{Results}

\section{Generation of transgenic rats}

Two constructs were used to generate transgenic rat lines (Fig. 1). Construct 1.5-Vßgal-0.2 was built from a $3.8 \mathrm{kbp}$ HindIII fragment that contains the entire VP structural gene (exons I, II and III; Fig. I), 1.5 kbp upstream of the start of hypothalamic transcription and $0.2 \mathrm{kbp}$ downstream of the pre-mRNA cleavage and polyadenylation site. A $3.0 \mathrm{kbp} \beta$-gal reporter element was inserted in frame into exon III with the consequent deletion of $66 \mathrm{bp}$ of sequences from this exon. A $\beta$-gal reporter was incorporated into the transgenes, rather than the chloramphenicol acetyl transferase (CAT) fragment previously used (Zeng ef al., 1994), to facilitate rapid identification of expressing cells in tissue sections (Sanes et al., 1986). The transgene was excised from vector and injected into fertilized one-cell eggs from Sprague-Dawley rats. Two independently derived founders were obtained and designated 1.5-V $\beta$ gal$0.2 \mathrm{~F} 1$ and $1.5-\mathrm{V} \beta$ gal-0.2F2. Construct $3-\mathrm{V} \beta$ gal- 0.2 was derived from $1.5-\mathrm{V} \beta \mathrm{gal}-0.2$ by the insertion of $1.5 \mathrm{kbp}$ of additional sequences upstream of the hypothalamic start of transcription (a total of $3 \mathrm{kbp}$ upstream of the start of hypothalamic VP gene transcription; Fig. 1). The transgene was excised from the vector and injected into fertilized one-cell eggs from SpragueDawley rats. Three independently derived founders were obtained and designated 3-VBgal-0.2F1-3. 


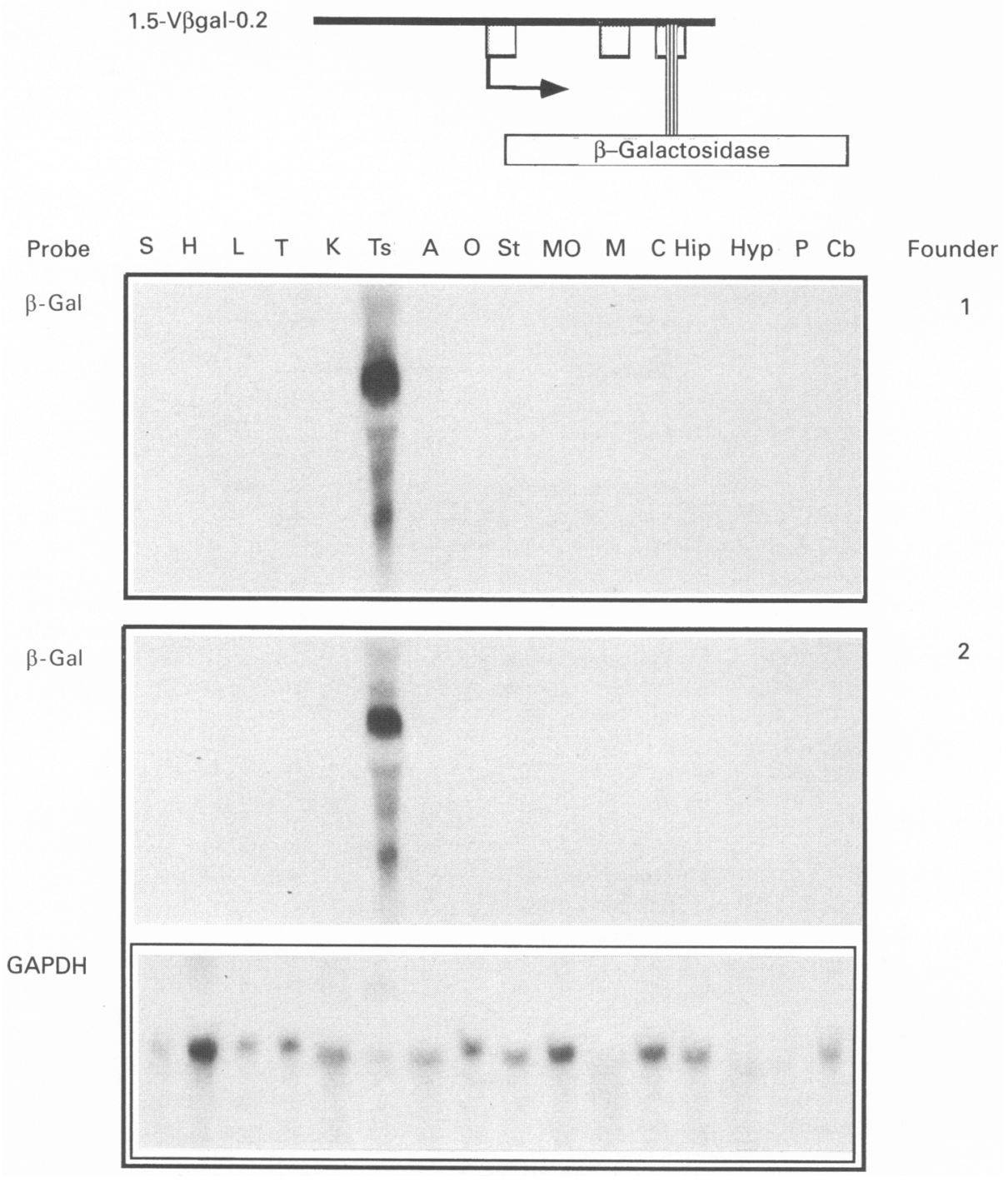

Fig. 2. Expression pattern of the 1.5-VBgal-0.2 transgene in rats. Total cellular RNAs from animals descended from founders 1 and 2 were extracted from spleen $(S)$, heart $(H)$, liver $(L)$, thymus $(T)$, kidney $(\mathrm{K})$, testis $(\mathrm{Ts})$, adrenal gland $(\mathrm{A})$, ovary $(\mathrm{O})$, striatum $(\mathrm{St})$, medulla oblongata and pons $(\mathrm{MO})$, midbrain $(\mathrm{M})$, cortex $(\mathrm{C})$, hippocampus (Hip), hypothalamus (Hyp), pituitary $(\mathrm{P})$ and cerebellum $(\mathrm{Cb})$. Males were used for all tissues except the ovary. $50 \mu \mathrm{g}$ RNA from each tissue was analysed by northern blotting and probed first with the full length $\beta$-gal gene, and then subsequently reprobed with a control oligonucleotide corresponding to glyceraldehyde-3-phosphate dehydrogenase (GAPDH), one example of which is shown (Line F2).

\section{Transgene expression}

RNA was extracted from a range of peripheral and brain tissues from all five founder transgenic lines and analysed by northern blotting (Figs 2 and 3). A full length $\beta$-gal probe revealed expression in the testes of all the lines. No expression could be detected in any other tissue, including the hypothalamus.

\section{Structure of testicular transgene transcripts}

Attempts to detect activity of $\beta$-galactosidase in sections of transgenic rat testes failed consistently, suggesting that the transgene RNAs were not translated. Examination of the northern blots (Figs 2 and 3) suggested that the transgene RNA was truncated, and hence could not encode a functional mRNA. The expected size of a mature VP- $\beta$-gal fusion RNA transcribed from the hypothalamic promoter is approximately $3.6 \mathrm{~kb}$. However, the major transgene transcript detected by the full length $\beta$-gal probe migrated at approximately $2 \mathrm{~kb}$, above the position of $18 \mathrm{~S}$ rRNA, which is approximately $1.874 \mathrm{~kb}$. Additional, smaller and lower abundance transgene RNAs were also detected by this probe (Figs 2 and 3). We then used a variety of specific probes to determine the gross structure of the testicular transgene transcripts (Fig. 4). An oligonucleotide probe corresponding to sequences in VP exon 
3-Vßgal-0.2
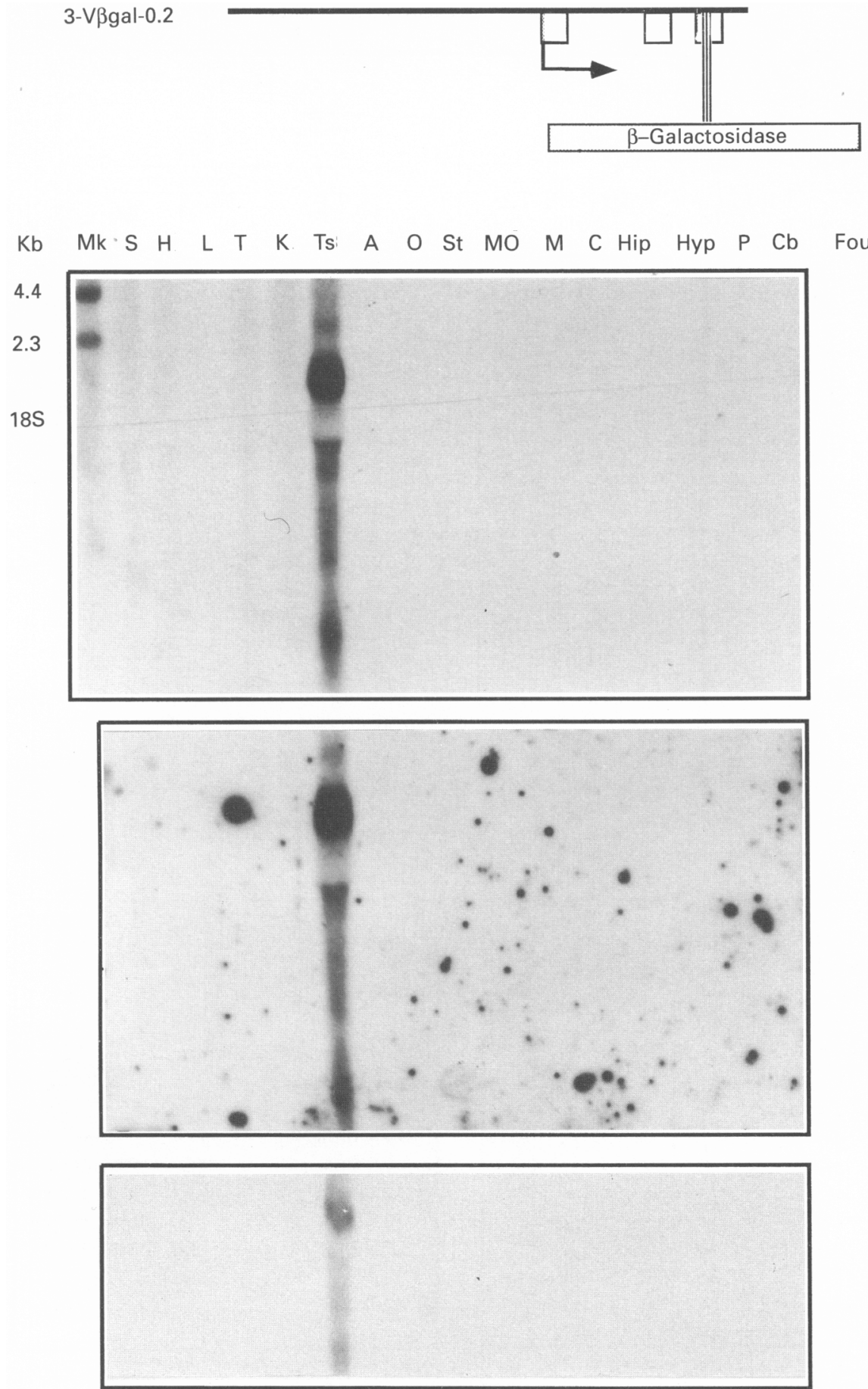

Fig. 3. Expression pattern of the 3-VBgal-0.2 transgene. Total cellular RNAs from animals descended from founders $1-3$ were extracted from spleen $(\mathrm{S})$, heart $(\mathrm{H})$, liver $(\mathrm{L})$, thymus $(\mathrm{T})$, kidney $(\mathrm{K})$, testis $(\mathrm{Ts})$, adrenal gland $(\mathrm{A})$, ovary $(\mathrm{O})$, striatum $(\mathrm{St})$, medulla oblongata and pons $(\mathrm{MO})$, midbrain $(\mathrm{M})$, cortex $(\mathrm{C})$, hippocampus (Hip), hypothalamus (Hyp), pituitary $(\mathrm{P})$ and cerebellum $(\mathrm{Cb})$. The track labelled $\mathrm{Mk}$ contained marker RNAs (Life Technologies, Paisley).

III (VP3') failed to detect transgene RNA while readily identifying the endogenous testicular VP-like RNAs. This was expected, as the sequences corresponding to this probe were deleted from the transgene by the insertion of the $\beta$-gal reporter. However, probes corresponding to VP exons I and II
(VP5' and VPNP respectively) also failed to detect the transgene RNAs. VP5' does not detect the endogenous testicular VP-like RNAs as exon I is not represented in these transcripts (Foo et al., 1991). The VPNP probe corresponding to exon II detected the endogenous VP-like RNAs as expected. All three 


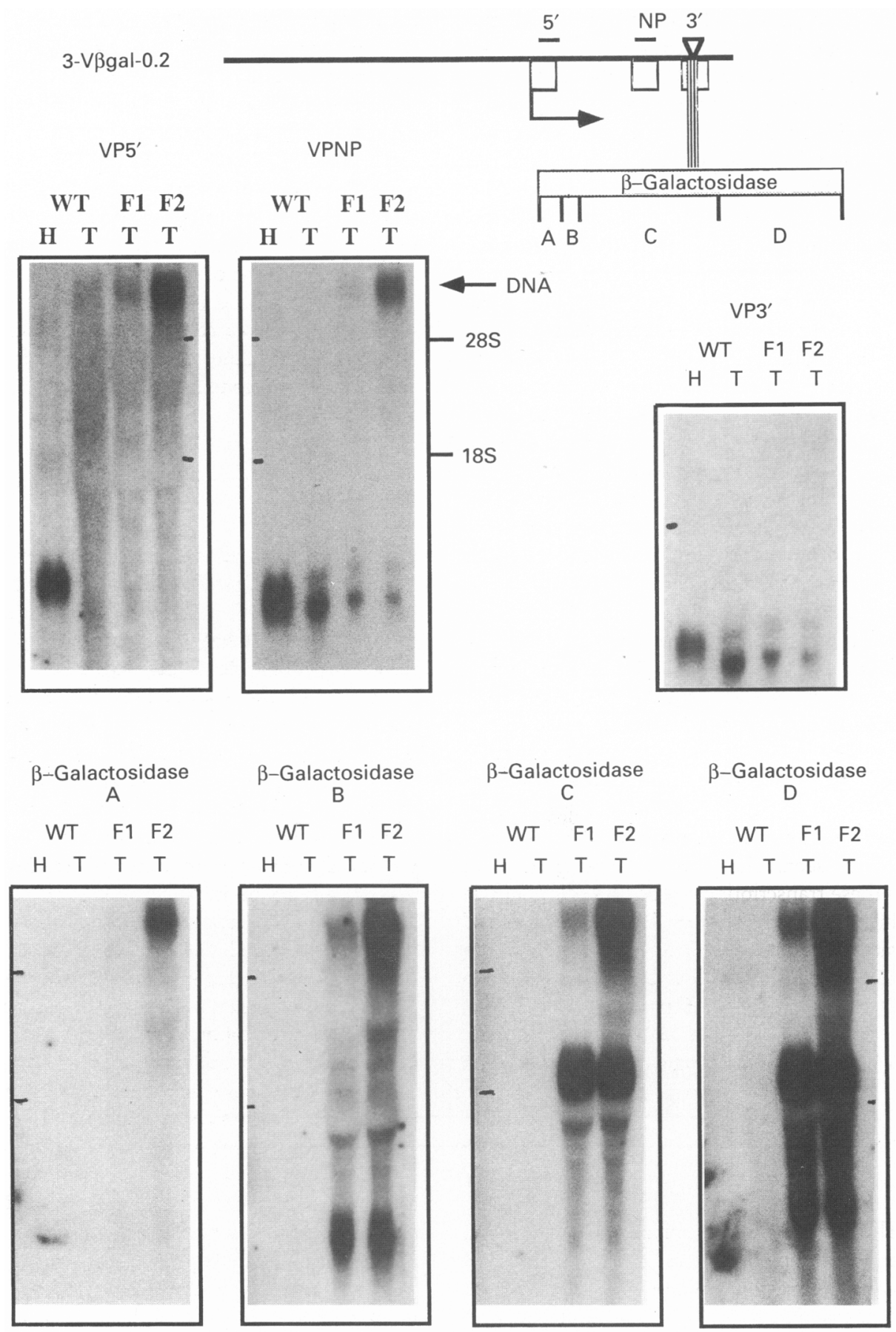

Fig. 4. Structure of the $\beta$-gal RNAs in transgenic rat testes. The locations of the probes used are shown on the map of the 3-V $\beta$ gal-0.2 transgene. The following oligonucleotide probes were used: rat VP exon I (VP5'); rat VP exon II (NP; which also detects the OT transcript); rat VP exon III (VP 3'). The following double-stranded DNA fragments corresponding to regions of the $\beta$-gal were used: fragment A: 438 bp defined by Pst I and Hpa Il sites; fragment B: 624 bp defined by Hpa II sites; fragment C: 890 bp defined by Hpa Il and Sst I sites; fragment D: 1126 bp defined by Sst I and Pst I sites. Fragments were labelled with ${ }^{32} \mathrm{P}$ by random priming. $5 \mu \mathrm{g}$ hypothalamic $(\mathrm{H})$ RNA from wild-type (WT) rats and $50 \mu \mathrm{g}$ of testicular (T) RNA from either wild-type (WT) or transgenic lines 3-V $\beta$-gal- 0.2 founder $I$ (F1) or founder 2 (F2) were analysed by northern blotting. The migration positions of $18 \mathrm{~S}$ and $28 \mathrm{~S}$ rRNAs are marked. Residual genomic DNA in the RNA preparations runs above the $28 \mathrm{~S}$ rRNA marker. 
probes detected the endogenous VP mRNA in the hypothalamus. The $\beta$-gal reporter was then divided into four fragments each of which was used as a probe to analyse testicular total cellular RNA from transgenic animals by northern blotting (Fig. 4). The major $2 \mathrm{~kb}$ transgene RNA was detected by probes $C$ and $D$, corresponding to the $3^{\prime}$ end of the reporter. Smaller RNAs of different sizes were detected by probes $\mathrm{D}$ and $\mathrm{B}$, but not by probe $\mathrm{C}$. Probe $\mathrm{A}$ failed to detect any of the transgene transcripts. The major $2 \mathrm{~kb}$ transgene RNA detected by probes $\mathrm{C}$ and $\mathrm{D}$ is polyadenylated (Fig. $5 \mathrm{a}$ ), as is the small RNA detected by probe D (Fig. 5a). None of the RNAs detected by probe B are polyadenylated (Fig. 5a). These data suggested that the transcription start point of the major $2 \mathrm{~kb}$ transgene transcript resided in fragment $\mathrm{C}$ and its use gives rise to a major polyadenylated RNA. Oligonucleotide probes corresponding to different regions of fragment $\mathrm{C}$ were then designed to map the transcription initiation point(s) of the transgene RNAs by primer extension. First, these oligonucleotides were used as northern hybridization probes to ensure that the sequences they correspond to were represented in the transgene transcripts. One such oligonucleotide ( $\beta$-galB), which detected the major $2 \mathrm{~kb}$ transgene RNA on northern blots (Fig. 5 b), revealed a number of specific run-off products, corresponding to putative transcription initiation sites, when used to primer extend transgenic testicular polyadenylated RNA (Fig. 5c; putative transcription initiation sites are shown on the sequence presented in Fig. 6). These extension products were not generated by extension of wild-type testicular polyadenylated RNA nor wild-type liver total cellular RNA using the same primer (Fig. 5c), although common, non-specific extension products were seen. The predicted size of the core RNAs derived from these transcription initiation sites would be around $1.5 \mathrm{~kb}$, which is much shorter than the observed transcript that migrates at about $2 \mathrm{~kb}$. However, removal of the poly(A) tail of the $2 \mathrm{~kb} \beta$-gal RNA by hybridization to oligo dT followed by RNase $\mathrm{H}$ digestion (Carrazana et al., 1988) resulted in core RNA(s) that migrated at $1.5 \mathrm{~kb}$ when compared with RNA size markers (Life Technologies, Paisley; data not shown).

\section{Germ cell expression of transgene RNA}

Lower abdominal heat treatment (Colins and Lacy, 1969), which results in germ cell depletion as judged by histological analysis (not shown) and a concomitant reduction in the VP-like RNAs in rat testis (Foo et al, 1994; Fig. 7a) resulted in a marked reduction in the level of transgene RNA (Fig. 7a), suggesting a germ cell origin for these transcripts. This was confirmed by in situ hybridization analysis using an oligonucleotide probe ( $\beta$-galA) corresponding to bases $2881-2828$ of the $\beta$-gal gene, which reside in fragment $D$ (Fig. 4). This oligonucleotide gives the same pattern as the fragment $D$ probe of the $\beta$-gal gene when used as a northern hybridization probe (Fig. 7a). The oligonucleotide probe revealed identical expression patterns in all five transgenic lines, with localization of the $\beta$-gal RNA in the seminiferous tubules (Fig. 7b). Examination of numerous sections revealed expression of the transgene in all tubular stages but at different levels. The 14 tubule stages (Le Blond and Clemont, 1952; Percy et al., 1961) are classified according to the steps of spermatogenesis present. The expression of the transgene was lowest in tubules of stages $1-7$ and highest in tubules at stages 8-14. Closer examination revealed that the signal was restricted to specific types of cell. Transgene expression abruptly increased between stages 7 and 8 with localization of $\beta$-gal RNA in the late pachytene layer. Transgene RNA concentrations remained high through the diplotene and diakynesis of primary spermatocytes, through the first meiotic division to the secondary spermatocyte stage and on into the second meiotic division. After meiosis, the $\beta$-gal RNA content of the round spermatids developing the acrosomal cap was low and decreased further as the spermatocytes started to elongate. Transgene RNA content dropped to undetectable values as elongation proceeded and as the spermatids condensed.

\section{Discussion}

We have introduced transgenes based on the rat VP gene into rats. Transgene 1.5-V $\beta$ gal-0.2 consists of the entire VP structural gene (exons I, II and III), $1.5 \mathrm{kbp}$ upstream of the start of hypothalamic transcription and $0.2 \mathrm{kbp}$ downstream of the polyadenylation site. So its expression could be distinguished from that of the endogenous VP gene, the transgene was marked by the insertion of a $3.0 \mathrm{kbp} \beta$-gal reporter element into exon III. Expression of this transgene was confined to the testis germ cells at particular stages of spermatogenesis. Extension of this transgene at the $5^{\prime}$ end by the addition of a further $1.5 \mathrm{kbp}$ of contiguous upstream sequences (3-V $\beta$ gal-0.2) did not alter this pattern. Germ cell expression of the transgene was shown to be initiated at cryptic promoter sites located within the $\beta$-gal reporter element, resulting in truncated and hence untranslated RNAs. We have also showed that the 3-Vßgal-0.2 transgene is active in the testes of mice (Mei Yin Ho, D. Murphy, D. A. Carter and Q. Zeng, unpublished).

Careful examination of the 1.5-Vßgal-0.2 and 3-Vßgal-0.2 lines failed to reveal expression of either transgene in the hypothalamus, suggesting that additional genomic sequences are required to elicit appropriate expression in the brain. These results are consistent with studies by Young et al. (1990), who demonstrated that a rat $\mathrm{VP}$ transgene similar to $1.5-\mathrm{V} \beta$ gal-0.2 was not expressed in the mouse brain. The 1.5-V $\beta$ gal-0.2VP transgene differs from the VP transgene described by Young et al. (1990) only in its possession of the $\beta$-gal reporter element, and the consequent deletion of $66 \mathrm{bp}$ from exon III. The finding that the 3-Vßgal-0.2 transgene also failed to be expressed in the hypothalamus suggests that the additional upstream sequences contained within this construct are not, at least on their own, important for hypothalamic expression. Genomic sequences crucial for the appropriate hypothalamic expression of the VP gene must reside either upstream or downstream of the confines of 3-Vßgal-0.2. We have previously described a VP genomic array that is regulated by appropriate cell-specific and physiological cues in the hypothalami of transgenic rats (Zeng et al., 1994). The 5-VCAT-3 transgene consists of the rat VP structural gene, containing a CAT reporter in exon III, flanked by $5 \mathrm{~kb}$ of upstream and $3 \mathrm{~kb}$ of downstream flanking sequences. Expression of 5-VCAT-3 is confined to VP, but not oxytocin, magnocellular neurones, 
(a)

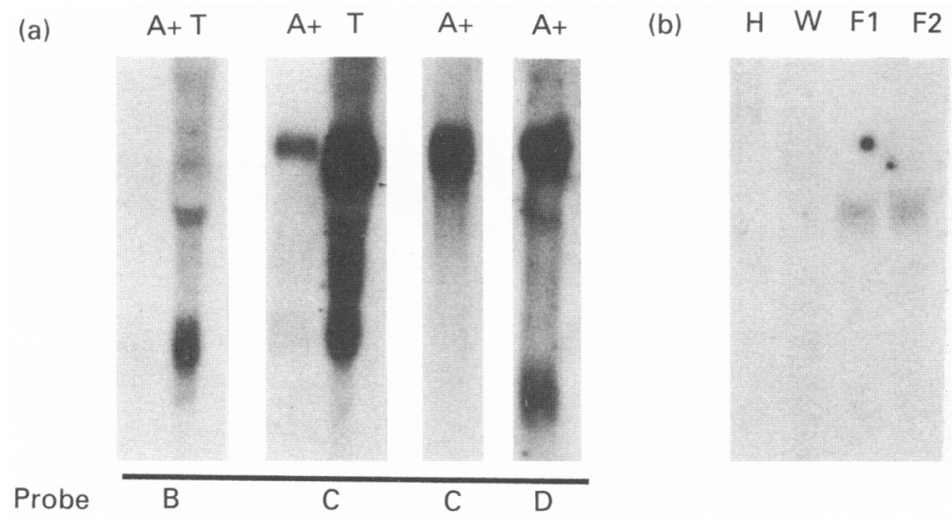

(b)

(c)

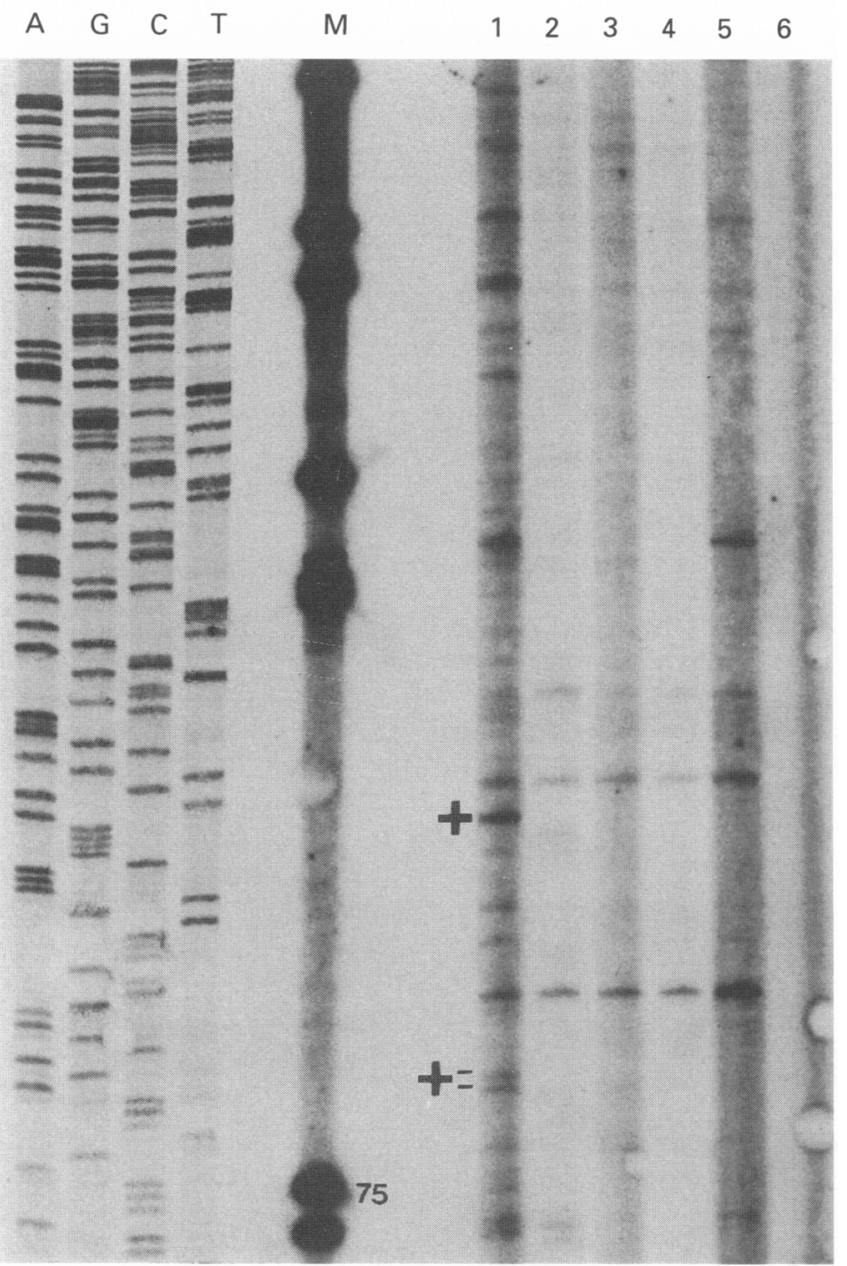

Fig. 5. (a) The major testicular $\beta$-gal RNAs are polyadenylated. Total ( $T ; 70 \mu g$ ) or poly (A) selected (A+: $1.2 \mu g$ ) RNA from line 3-VBgal-0.2 founder $I$ were subjected to northern analysis. The northern filters were hybridized to fragments of the $\beta$-gal gene. (b) Primer extension oligonucleotide $\beta$-gailB detects a single RNA size class in transgenic testicular RNA. $5 \mu$ g of hypothalamic (H) RNA from wild-type rats and $50 \mu g$ of testicular RNA from either wild-type (W) or transgenic lines 3-V $\beta$ gal-0.2 founder I (FI) or founder 2 (F2) was analysed by northern blotting. The northern filter was hybridized to the $\beta$-galB probe at $45^{\circ} \mathrm{C}$. (c) Primer extension analysis of the $5^{\prime}$ end of the testicular $\beta$-gal RNA in transgenic rat testes. The following RNA samples were subjected to primer extension analysis: track 1 , poly $(A)$ selected testicular RNA ( $30 \mu g)$ from 3-Vßgal-0.2 founder 1; track 2, total cellular testicular RNA (100 $\mu$ g) from 3-Vßgal-0.2 founder 3; track 3, poly(A) selected testicular RNA (30 $\mu$ g) from wild-type rat; track 4 , total cellular testicular RNA $(100 \mu \mathrm{g})$ from wild-type rat; track 5 , total cellular liver RNA (100 $\mu \mathrm{g})$ from wild-type rat; track 6, no RNA. RNAs were annealed to oligonucleotide $\beta$-galB and extension products were analysed on a $6 \%$ ( $w / v)$ denaturing polyacrylamide gel. No RNA was included in the extension reaction fractionated in track 6 . Markers were the ' 1 kb ladder' (Life Technologies, Paisley; track M). Marker sizes in bases are indicated. The sequence of the $\beta$-gal gene using oligonucleotide $\beta$-galB as a primer was run on the left ladder of the gel (AGCT). The common bands correspond to non-specific extension from RNA(s) common to all samples. The bands marked by $(+)$ correspond to the most prominent extension products only found with transgenic rat testis RNA, the positions of which are shown in Fig. 6 . Other, less abundant, higher molecular weight products were also generated by the use of multiple initiation sites. 
(a)

\begin{tabular}{|c|c|c|c|c|c|c|}
\hline & 1436 & & & 1541 & & \\
\hline & $\begin{array}{l}----+---v-v-1-+-1-v \\
\text { ATCCTTCCCGCCCGGTGCAG }\end{array}$ & & & $\begin{array}{l}---1+-1-v-1--+1--v \\
\text { GAAGACCAGCCCTTCCCGGC }\end{array}$ & & $\beta-\mathrm{Gal}$ \\
\hline-105 & $\triangle A C C T T C C C T A G G A G A G A A G$ & -86 & -89 & GAAGACTCAGTGCAGAAGAG & -70 & rAVP \\
\hline+23 & TGTCITCCCTGGCGTCGGTT & $+4 \Leftarrow$ & +36 & GAAGACAGGGCGCCCTCGGA & +55 & rENK \\
\hline
\end{tabular}

(b)

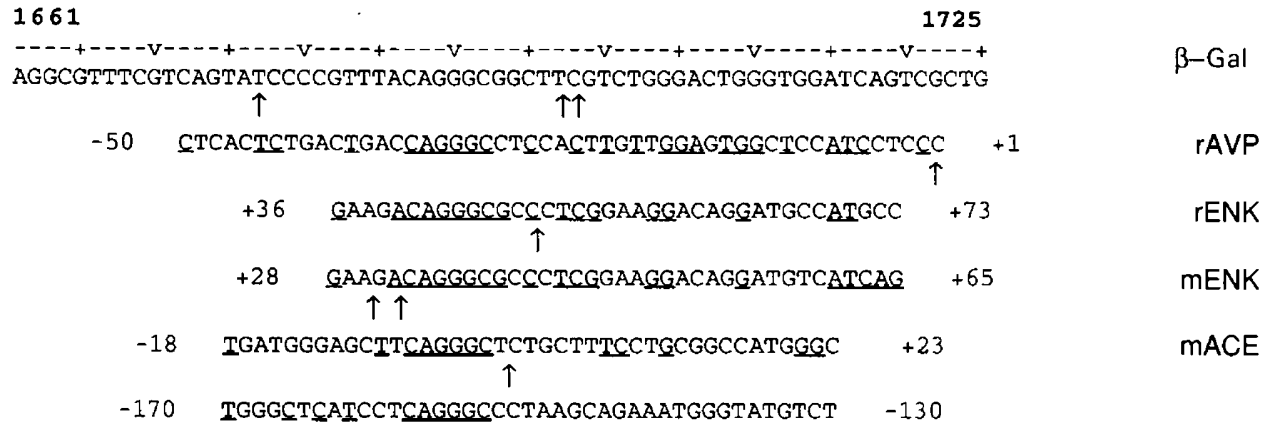

Fig. 6. $\beta$-Gal testis-specific promoter sequence motifs are found in other germ cell promoters. The sequence of the putative testicular promoter identified in the $\beta$-gal gene was compared with the sequences of a number of germ cell-specific promoters. Only those motifs found in three promoters are presented. (a) Alignment of the rat VP testis promoter with similar sequences found in germ cell promoters of the rat VP gene (rAVP) and the rat preproenkephalin gene ( $\mathrm{EENK}$ ). The numbering of the $\beta$-gal sequence is from Kalnins et al. (1983). The numbering of the rAVP and rENK sequences represent distances from the most $5^{\prime}$ initiation site of testicular transcription. The horizontal arrow indicates that the sequence is derived from the complementary DNA strand. Underlined nucleotides are identical to the corresponding $\beta$-gal sequence. (b) Comparison of regions surrounding the CAGGGC motifs identified in a number of testicular promoters: $\mathrm{A} A \mathrm{P}$, rat vasopressin; rENK, rat preproenkephalin; $\mathrm{mENK}$, mouse preproenkephalin; $\mathrm{mACE}$, mouse angiotensin converting enzyme. Position numbers correspond to the distance from the most $5^{\prime}$ initiation site of testicular transcription. The numbering of the $\beta$-gal sequence is from Kalnins et al. (1983). Underlined nucleotides are identical to the corresponding $\beta$-gal sequence. Vertical arrows correspond to mapped transcription initiation sites.

within which it is regulated by osmotic stimuli. Grant $e t$ al. (1993) showed that a rat transgene consisting of the VP structural gene, $3 \mathrm{kbp}$ of downstream sequences and $3 \mathrm{kbp}$ of upstream sequences is expressed in the hypothalamus of one line of mice, although expression was not shown to be confined to vasopressinergic neurones. Together, these data suggest that sequences required for expression of the VP gene in magnocellular neurones reside in the $3 \mathrm{kbp}$ downstream of the rat VP gene.

The $\beta$-galactosidase ( $\mathrm{LacZ}$ ) gene has been used as a reporter in many transgenic mouse lines, although this is the first report of its use in rats. It is popular because of the ease of detection of its protein product in transgenic tissues, and the assumption that it has a neutral effect on the activity of mammalian regulatory elements. The vast majority of transgenic studies using the $\beta$-gal reporter have relied on the detection of enzyme activity rather than the expression of the transgene RNA. However, in two cases it has been reported that transgenes containing $\beta$-gal are expressed in the testis, and in both cases unexpected size classes of RNA were described. Borsook et al. (1992) described the expression in mice of a fusion gene consisting of $3 \mathrm{kbp}$ of $5^{\prime}$ sequences and $1.4 \mathrm{kbp}$ of $3^{\prime}$ sequences derived from the human preproenkephalin gene. In addition to a large transcript that was presumed to be initiated from the normal human preproenkephalin promoter, an additional abundant smaller transcript was observed to migrate just above the $18 \mathrm{~S}$ rRNA marker. Forss-Petter et al. (1990) described a similar pattern of expression for a transgene made up of the rat-neurone-specific enolase promoter linked to $\beta$-gal. It is likely that the smaller transgene transcript described by these authors is derived from the same cryptic germ-cellspecific initiation site contained within the 1.5-Vßgal-0.2 and 3-Vßgal-0.2 transgenes.

The use of a germ-cell-specific cryptic promoter in the transgenic rat lines described here is similar to the many unusual transcriptional events that have now been documented to take place in male germ cells (Ivell, 1992). A characteristic of spermatogenic-cell gene expression is the presence of germ-cell-specific transcript forms not found in somatic cells. These RNAs are the result of the use of transcriptional and post-transcriptional regulatory signals that are uniquely recognized in the cells of the male germ line. For example, the major RNA products of the VP gene in rat testis are a family of untranslated transcripts that do not contain exon I and thus cannot encode the VP nonapeptide (Foo et al., 1991, 1994). The testis VP-like RNAs are generated by differential splicing events that link combinations of four testis-specific exons (none of which are represented in the 3-VBgal-0.2 and 
(b)
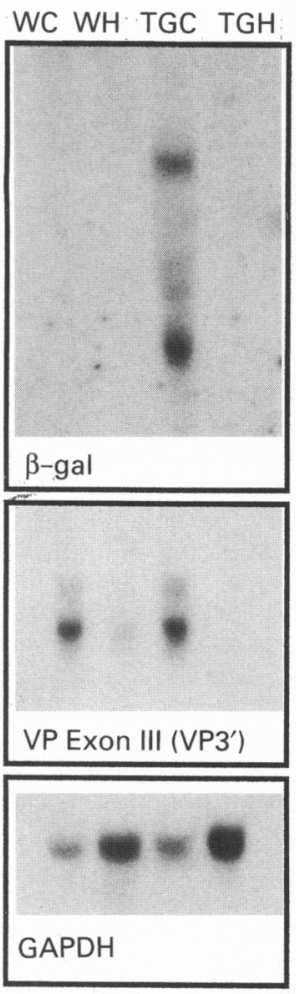
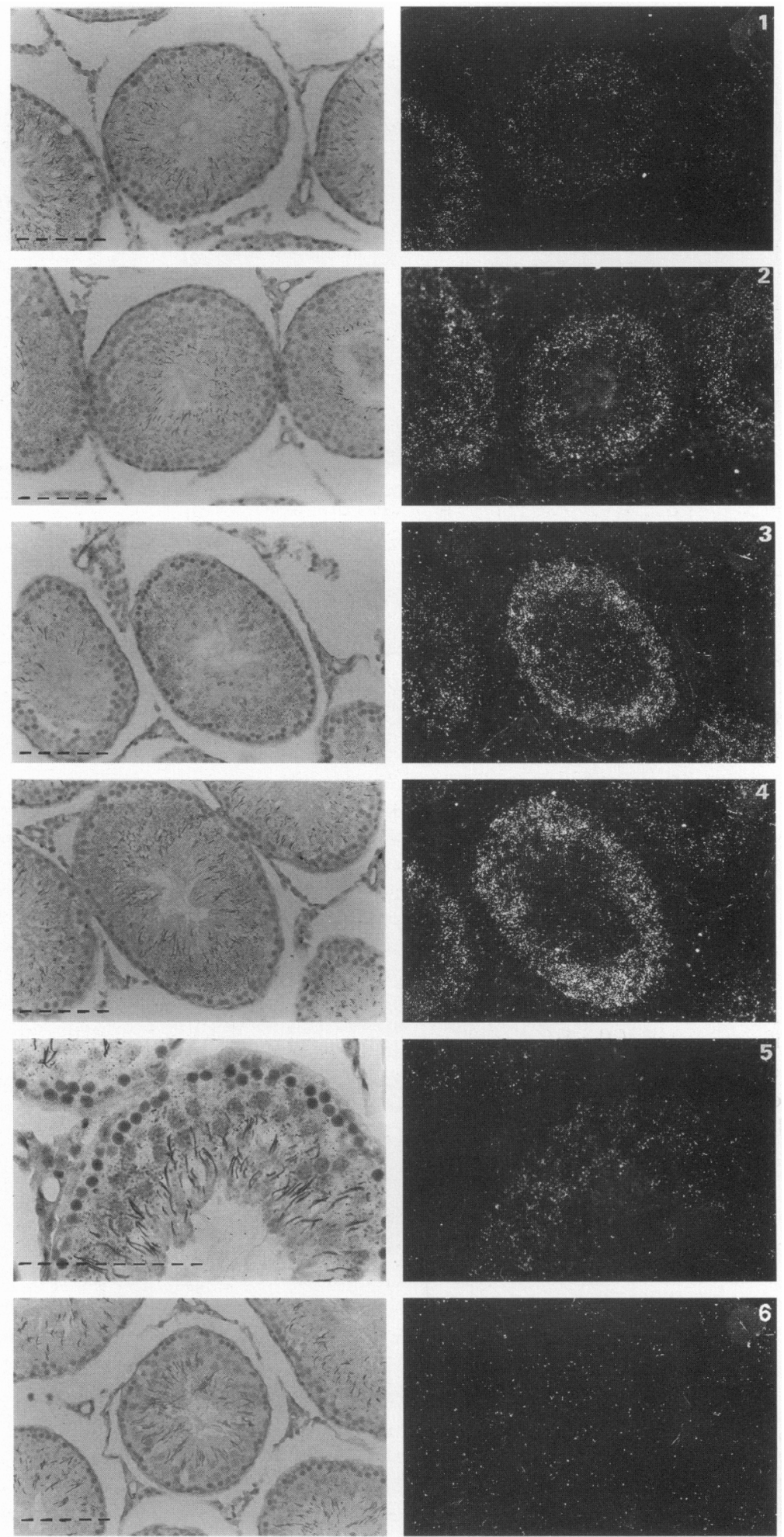

Fig. 7. (a) Depletion of $\beta$-gal RNA in transgenic rat testes following scrotal heat treatment. Testicular RNA was extracted from 60 day old wild-type (W) or $3 \mathrm{VB}$-gal-0.2 rats that had been subject to no treatment (controls; C) or to lower abdominal heat treatment $(\mathrm{H}$ ). $100 \mu \mathrm{g}$ of total RNA was subjected to northern analysis. The northern filter was consecutively probed with oligonucleotides corresponding to fragment $D$ of the $\beta$-gal gene (oligonucleotide $\beta$-gaiA; $\beta$-gal); exon III of the rat VP gene (VP3') and GAPDH. (b) In sifu detection of $\beta$-gal RNA in sections of testis of 3 -VBgal-0.2 transgenic rats using the $\beta$-galA oligonucleotide as a probe. Bright-field photomicrographs (left) show cross sections of tubules, the cells within defining the stage. Dark-field pictures (right) show the autoradiographic signal (21 day exposure except for picture 5 that was exposed for 17 days) seen in the same tubule. 1 , stage $3 ; 2$, stage $7 ; 3$, stage $10 ; 4$, stage $13 ; 5$, high magnification, stage $13 ; 6$, wild-type rat, stage 13. Stages $8-14$ have the highest signal due to high expression in late pachytene cells starting in stage 8 tubules and continuing through both meiotic divisions seen in stage 14 tubules (see pictures 3-5). After meiosis the transgene is expressed at a lower level in the round spermatids developing the acrosomal cap. These round cells are seen in tubule stages 1-8 (pictures 1 and 2). When these cells start to elongate (stages $8-10$ ) the expression level drops. Note that in the stage 10 tubule (picture 3) the inner layer shows this lower signal whilst the outer layer shows the high expression of the late pachytene cells. The elongating spermatocytes seen in stages II-14 no longer express the transgene as demonstrated by the lack of signal over the inner layers of the stage 13 tubule (pictures 4 and 5). The wild type rat tubule at stage 13 (picture 6 ) shows no

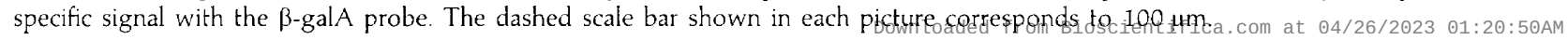


1.5-Vßgal-0.2 transgenes) to exons II and III of the corresponding hypothalamic VP gene transcript (Foo et al., 1991; Fig. 1). The expression of the novel VP-like RNAs in rat testis was shown to be closely associated with the integrity of germ cells and ongoing spermatogenesis as germ cell depletion markedly reduced their expression (Foo et al, 1994). The testis-specific VP promoter is not contained within the transgenes used in this study. We compared the sequence of the cryptic germ cell promoter found within $\beta$-gal with the testicular promoter of a number of genes, including rat VP (Foo ef al., 1994). Like the promoter contained within $\beta$-gal, these germ cell promoters do not use a TATA box and contain multiple transcription initiation sites. Motifs previously identified as being present in the testicular promoters of rat VP (Foo et al., 1994) and rat and mouse preproenkephalin (Kilpatrick et al., 1987, 1990) genes were also identified in the region of the $\beta$-gal germ cell promoter (Fig. 6). Particularly striking is the presence of a CAGGGC motif in the immediate vicinity of the $\beta$-gal testicular initiation sites. This sequence is also found in a similar position in the rat and mouse enkephalin, rat VP and mouse angiotensin converting enzyme (Howard et al., 1993) germ cell promoters (Fig. 6; Foo et al., 1994). Juxtaposed to the CAGGGC are TC motifs that define, or are close to, mapped transcriptional start sites (Fig. 6). Galcheva-Gargova et al. (1993) demonstrated the presence in germ cell nuclear extracts of DNA binding proteins that can form specific complexes with a 28 bp oligonucleotide from the rat enkephalin testis promoter containing this motif. It is not known whether these complexes act autonomously to initiate germ cell transcription, or depend upon an interaction with distal enhancer elements contained within the VP gene. Whatever mechanism is involved, the male germ-cell-specific promoter of the VP- $\beta$-gal transgenes offers a model for the study of the mechanisms whereby an epigenetic choice is made between the use of a germ cell or a somatic promoter, and the stage-specific transcriptional regulation of the germ cell promoter during spermatogenesis.

The authors thank S. Jones and her staff in the IMCB Animal Holding Unit for their care of the rats used in this study; F. Leong for photography and A. Ratty and K. Tabiti (IMCB) for their comments on the manuscript.

\section{References}

Ang H-L, Ungefroren H, de Bree F, Foo N-C, Carter D, Burbach JPH, Ivell R and Murphy D (1991) Testicular oxytocin gene expression in seminiferous tubules of cattle and transgenic mice Endocrinology 128 2110-2117

Borsook D, Rosen H, Collard M, Dressler H, Herrup K, Comb MJ and Hyman SE (1992) Expression and regulation of a proenkephalin- $\beta$-galactosidase fusion gene in the reproductive system of transgenic mice Molecular Endocrinology 6 1502-1512

Carrazana EJ, Pasieka KB and Majzoub JA (1988) The vasopressin poly(A) tail is unusually long and increases during stimulation of vasopressin gene expression in vivo Molecular and Cell Biology 8 2267-2274

Clemens MJ (1984) Purification of eukaryotic messenger RNA. In Transcription and Translation. A Practical Approach, pp 21I-230 Eds BD Hames and SJ Higgins. IRL Press, Oxford

Collins P and Lacy D (1969) Studies on the structure and function of the mammalian testis II. Cytological and histochemical observations on the testis of the rat after a single exposure to heat applied for different lengths of time Proceedings of the Royal Society of London Series B 172 17-38

Foo N-C, Carter D, Murphy D and Ivell R (1991) Vasopressin and oxytocin expression in rat testis Endocrinology 128 2118-2128
Foo N-C, Funkhouser JM, Carter DA and Murphy D (1994) A testis-specific promoter in the rat vasopressin gene Journal of Biological Chernistry 269 659-667

Forss-Petter S, Danielson PE, Catsicas S, Battenberg E, Price J, Nerenberg $M$ and Sutcliffe JG (1990) Transgenic mice expressing $\beta$-galactosidase in mature neurons under neuron-specific enolase promoter control Neuron 5 187-197

Fort P, Marty L, Piechaczyk M, El Sabrouty S, Dani C, Jeanteur P and Blanchard JH (1985) Various rat adult tissues express only one major mRNA species from the glyceraldehyde-3-phosphate dehydrogenase multigene family Nucleic Acids Research 13 1431-1442

Galcheva-Gargova Z, Tokeson JP, Karagyosov LK, Elbert KM and Kilpatrick DL (1993) The rat proenkephalin germ line promoter contains multiple binding sites for spermatogenic cell nuclear proteins Molecular Endocrinology 7 979-991

Grant FD, Reventos J, Gordon JW, Kawabata S, Miller M and Majzoub JA (1993) Expression of rat arginine vasopressin gene in transgenic mice Molecular Endocrinology 7 659-667

Howard TE, Shai S-Y, Langford KG, Martin BM and Bernstein KE (1990) Transcription of testicular angiotensin converting enzyme (ACE) is initiated within the 12th intron of the somatic ACE gene Molecular and Cell Biology 10 4294-4302

Ivell R (1992) "All that glisters is not gold" - common testis gene transcripts are not always what they seem International Journal of Andrology 15 85-92

Ivell $\mathbf{R}$ and Burbach JPH (1991) The molecular biology of vasopressin and oxytocin genes Journal of Neuroendocrinology 3 583-585

Kalnins A, Otto K, Ruther U and Muller-Hill B (1983) Sequence of the Lac Z gene of Escherichia coli. The EMBO Journal 2 593-597

Kilpatrick DL, Borland K and Jin DF (1987) Differential expression of the opioid peptide genes by testicular germ cell and somatic cells Proceedings of the National Academy of Sciences, USA 84 5695-5699

Kilpatrick DL, Zinn SA, Fitzgerald M, Higuchi H, Sabol SL and Meyerhardt J (1990) Transcription of the rat and mouse proenkephalin gene is initiated at distinct sites in spermatogenic and somatic cells Molecular and Cell Biology 10 3717-3726

Le Blond CE and Clermont Y (1952) Spermatogenesis in the rat, mouse, hamster and guinea pig as revealed by the periodic acid fuchsin sulfurous acid technique American Journal of Anatomy 90 167-215

Lefebvre DL and Zingg HH (1991) Novel vasopressin gene-related transcripts in rat testis Molecular Endocrinology 5 645-652

Lightman SL and Young III WS (1987) Vasopressin, oxytocin, dynorphin, enkephalin and corticotrophin releasing factor mRNA stimulation in the rat Journal of Physiology 394 23-39

Murphy D and Carter DA (1993) Transgenesis Techniques. Principals and Protocols, Human Press, Totowa, NJ

Murphy D and Hanson J (1987) The production of transgenic mice by the microinjection of fertilised one-cell eggs. In DNA Cloning. A Practical Approach Volume III, pp 213-248 Ed. DM Glover. IRL Press, Oxford

Murphy D, Levy A, Lightman S and Carter D (1989) Vasopressin RNA in the neural lobe of the pituitary: dramatic accumulation in response to saltloading Proceedings of the National Academy of Sciences, USA 86 9002-9005

Percy B, Clermont $Y$ and Le Blond CP (1961) The wave of the seminiferous epithelium in the rat American Journal of Anatomy 108 47-77

Sambrook J, Fritsch EF and Maniatis T (1989) Molecular Cloning: A Laboratory Manual. Cold Spring Harbor Laboratory, Cold Spring Harbor, New York

Sanes JR, Rubenstein LR and Nicholas J-F (1986) The use of recombinant retroviruses to study post-implantation cell lineage in mouse embryos The EMBO journal 5 3133-3142

Treizenberg SJ (1990) Primer Extension. In Current Protocols in Molecular Biology Volume 1, pp 4.8.1-4.8.5 Eds FM Ausubel, R Brent, RE Kingston, DD Moore, JG Seidman, JA Smith and K Struhl. John Wiley and Sons, New York

Willison K and Ashworth A (1987) Mammalian spermatogenic gene expression Trends in Genetics 3 351-355

Young III WS (1992) Expression of the vasopressin and oxytocin genes Journal of Neuroendocrinology 4 527-540

Young III WS, Reynolds K, Shepard EA, Gainer H and Castel M (1990) Cell specific expression of the rat oxytocin gene in transgenic mice Journal of Neuroendocrinology 2 915-925

Zamboni L and De Martino C (1967) Buffered picric acid-formaldehyde, a new rapid fixative for electron microscopy Journal of Cell Biology 35 148A

Zeng Q, Carter DA and Murphy D (1994) Cell specific expression of a vasopressin transgene in rats Journal of Neuroendocrinology 6 469-477 